http://www.jfas.info

\title{
CONSTRUCT VALIDITY AND RELIABILITY OF AUTOMATED BODY REACTION TEST
}

\author{
N. Salimin ${ }^{1 *}$, M. I. Shahril ${ }^{1}$, M. A. Mdtaff ${ }^{1}$, G. Elumalai ${ }^{1}$, R. Ahmad ${ }^{1}$, H. M. Hizan ${ }^{1}$, A. \\ Hashim $^{1}$, M. F. Abdullah ${ }^{1}$ and S. K. Syed Ali ${ }^{2}$ \\ ${ }^{1}$ Faculty of Sports Science and Coaching, Universiti Pendidikan Sultan Idris, Tg Malim, \\ Perak, Malaysia \\ ${ }^{2}$ Faculty of Education, University of Malaya, Malaysia
}

Published online: 10 November 2017

\begin{abstract}
Automated Body Reaction Test (ABRT) is a new device for skills and physical assessment instrument to measure ability on react, move quickly and accurately in accordance with stimulus. A total of 474 subjects aged 7-17 years old were randomly selected for the construct validity $(\mathrm{n}=330)$ and reliability $(\mathrm{n}=144)$. The ABRT score were correlated with Nelson Choice Reaction Time test to find out the validity and reliability test conducted by using test and retest prosedures. Finding of the study shows that the validity for students age 7-9 years $(\mathrm{r}=0,73), 10-12$ years $(\mathrm{r}=0.87), 13-15(\mathrm{r}=0.87)$ and 16-17 years $(\mathrm{r}=0.89)$ meanwhile for reliability for students age 7-9 years $(\mathrm{r}=0,90), 10-12$ years $(\mathrm{r}=0.87), 13-15(\mathrm{r}=0.88)$ and 16-17 years $(\mathrm{r}=0.88)$. Based on the finding, ABRT showed highly validity, reliability and acceptable as a new instrument to measure reaction time on healthrelated fitness.
\end{abstract}

Keywords: validity; reliability; reaction time; physical fitness

Author Correspondence, e-mail: norkhalid@fsskj.upsi.edu.my doi: http://dx.doi.org/10.4314/jfas.v9i6s.89 


\section{INTRODUCTION}

Physical fitness based on health and motor skills through systematic and orderly sports activities are essential to both the physical and mental aspects of an individual. A person's fitness can affect his ability to perform a motor skill either in sports or game activities. A healthy body is also one of the determining factors of the perfect and well life. Motor skills are very important in every game involved so that the activity done does not cause problems to movement and injury.

Physical fitness is referred as the ability to perform daily tasks and responsibilities without getting fatique, still have energy to engage in leisure activities and face any potential emergency. Physical fitness is described based on two components, namely health related fitness and skilled related fitness.Physical fitness related health includes aspects related to psychological and physiological functions. The components of physical health related fitness are cardiovascular endurance, muscle endurance, flexibility and body composition [1]. These components are believed to be able to protect individuals from hypokinetic diseases (lack of movement) such as obesity, muscle and bone related diseases and cardiovascular diseases.

Skilled related components of physical fitness are referred as the individual's function and ability to compete in sports activities with more energy, power and skill. This component covers speed, agility, balance, power, reaction time and coordination aspects. Both aspects of physical fitness symbolize the overall quality of life of the individual. Therefore, in order to succeed in a sports field, these two elements are very important and should be highlighted. The combination of both elements will bring the best results in playing sports.

Body Reaction is the time taken by an individual to respond after receiving stimulus to do so. While the reaction time test can be used to determine the coordination level of an individual. There are three types of reaction time tests, that are Nelson Reaction Test and Nelson Hand Reaction Test and Crazy Reaction Ball Test (Ball Drop) test.

There are five phases of motor movement according to age group include the reflexive phase, pre-adapted motor patterns phase, fundamental motor skills phase, contex-specific motor skills phase and skillfillness phase. The reflexive phase is when someone is newly-born to 2 weeks old. At this phase the individual will respond to surrounding stimuli including touch, sound and temperature. This stage is very important to the motor development of an 
individual before moving to the next phase.Pre-adapted motor patterns phase phase is the stage where an individual of 2 weeks old to 1 year old begins to learn to control their behavior. The third phase is fundamental motor skills in which at the age of one to 7 years, the individual will reinforce the movement learned in the previous phase.The fourth phase is contex-specific motor skills phase (7-11 years old). In this phase, individuals begin to learn more movements by combining some of the previously learned movements. The fifth phase is at the age of 11 years old, the individual will combine all the skills and experience gained to master the movement. During skill management phase, individuals will experience injuries or accidents that may cause the individual unable to master the desired skills. This phase is named as a compensation phase. When an individual is at that phase, they will re-combine all the movements learned to master all movements [2].

Improving skills is one of the reasons why individuals engage in sports [3]. Model Gentile divides the skill mastery level into two levels, namely initial stage and later stage. The initial stage is a new level or an early stage of acquiring an idea to learn a skill. At this stage, mental will operate to understand the skills that need to be mastered and learned. Cognitive verbally will trigger the idea before being followed by translation through action. The actors will begin to determine the necessary and unnecessary actions depending on the environment.The second stage is the later stage which is the stage where the individual begins to know the way to conduct an exercise or skill effectively. At this stage individuals also begin to adapt and reinforce their skills and focus more on improving performance. Individuals will also be consistent with the skills gained so that goals are achieved. On the other hand, as an athlete, the skills required are varied and vary depending on the situation and the environment. For children aged 10 to 12 , at this age level, physical fitness based on motor skills is a very important aspect of everyday life. This is because physical fitness based on motor skills is also influenced by their daily lives [4].

The study found that children with low motor performance would be less likely to be accepted by peers during physical activity. In addition, children with poor motor performance will also feel that they are unable to compete in physical activity and are not free in performing leisure activities. Hence, the role of physical fitness performance based on motor skills is very important in the course of everyday human life [5]. The study also found that children with 
low motor skills would be less involved with sports and recreation activities [6].The studyon motor skills and antipolemic parameters among children aged 6 to 12 years was found that the body mass index (BMI) factor was not significantly influenced by an individual's physical fitness based on motor skills. This is because motor fitness is influenced by age factor and gender [7].

Reaction time defined as the interval of the time between the presentation of the stimulus and the initiation of the response. Reaction varies from individual to individual. The ability of an individual to react to an external stimulus shows the level of his neuro-muscular coordination. A faster or slower reaction and / or movement is a good or poor ability to coordination and the use of limbs and body depends on the type of games play situations and type of action to move or to react to the objects. Reaction time of an individual is liable to vary according to special physical activity in which he participates. The response time or reaction of an individual is actually closely related to mental and physical. Therefore, to ensure that one's response time is effective, the focus should be on mental and physical [8].

Several previous researchers have studied to observe the relationship resulted between adult support to the physical activity of children and their effects. A study to evaluate Manchester motor skills program to help children with motor problems. This program was collaboration with educational psychologist (EPs), trained teachers and a few selected schools. The program is an early intervention measure used to help children with physical fitness based on motor skills problems. The children involved in the program were assessed via pre and post-tests. The results show a positive improvement in children's motor skills when the school provided a high commitment and consistency in performing various physical fitness tests against children who have been identified as having physical intelligence problems based on motor skills. The study has also confirmed that the commitment of all parties has a significant relationship with the physical fitness of children based on motor skills [9].

A study to assess the relationship of physical fitness based on motor skills and children's perceptions of their ability during the first year of schooling. A total of 260 subjects were involved in this study. To measure the physical fitness based on motor skills, the tests used are Test of Gross Motor Development-2, while the perceptions of children involved are measured using Pictorial Scale of Perceived Competence and Social Acceptance of Young Children. The 
results showed that although physical fitness based on motor skills was low, these children still had a positive perception of their ability in physical activity. This will lead to opportunities to improve their muscle skills in the future [10].

A studies on 11 years to 17 years old children in Finland who play football and do not play football. Two control groups were conducted and the test was conducted for two years. The battery test component involved in testing physical fitness based on the motors skills used in this study was agility, speed, power, balance and reaction time. The findings show that children involved in physical fitness activities based on motor skills by playing football had a better physical resistance level compared to the control group who were not involved in football game, especially in resistance to cardiovascular problems [11].

Recent studies on physical fitness based on motor skills in Malaysia was conducted to identify the effectiveness of physical fitness training based on motor skills on University Teknologi Malaysia (UTM) hockey athletes [12]. The fitness levels of 22 subjects comprising 11 men and 11 women were measured through six battery tests based on motor skills using Hand and Eye Coordination Test, 30 Meters Run Test, Standing Stork Test, Illinois Agility Test, Nelson Foot Reaction Test and Standing Long Jump Test. This study involved pre-test and post-test. The results showed that data from post-test for male and female athlete performance indicated improvement through all tested components. For male athletes, the coordination, agility and balance components showed improvement but were at moderate level. The components of speed, reaction time and power showed an improvement at a good level. Whereas for female athletes, speed showed improvement but it was at a weak level by the original norm and the power component was still below the moderate level. The coordination, balance and agility components were at moderate levels and reaction time showed good improvement.

Another study in the country conducted to identify physical fitness based on motor skills level for the basketball team of SekolahTun Fatimah [13]. The subjects were girls aged 15 to 17 years old. A total of 10 basketball players were chosen as sample in this study. The tests used were the Basketball Dribbling Test for coordination component, 30 meter Sprint Test for speed component, Standing Stork Test for balance component, Back and Forth Run Test for agility component, Nelson Reaction Test for reaction time component and Vertical Jump Test for power component. The subjects have undergone Pre-Test, Basketball-specific training 
program for six weeks and followed by Post Test. All the data obtained from the test performed by the sample were recorded in the score form and set the achievement based on the predetermined norm. The findings show that there was a significant difference between Pre and Post Test for all physical fitness tests based on motor skills. The researchers concluded that the six-week training program had influenced the physical fitness based on motor skills of the basketball team of SekolahTun Fatimah, Johor Bahru.

An instrument or measuring instrument is considered valid when it really measures what is supposed to be measured. If a test is conducted using an invalid measurement, the data obtained cannot be used because the data is invalid. In performing a reaction time test, the researcher or the tester should be confident that the instrument used measures what is supposed to be measured so that the data obtained are valid and applicable [14]. The diverse measurements led to the existence of various types of validity and among them are the logical validity, content validity, criteria validity and construct validity [15]. Most physical fitness measurements in Physical Education adopt a correlation coefficient of 0.80 and above. Construct validity is usually associated with the results of the study on some behavioral characteristics. Construct validity are obtained based on scientific methodology with the use of various statistical procedures such as statistical factor analysis. This method is usually used to determine or identify the basic components of fitness or sports skills [16].

Concept of reliability refers to the extent to which the measurement tool produces consistent results and reliability in a measurement refers to the ability of the instrument to obtain a similar value when the same measurement is repeated and has a consistency. A good instrument is that the score results have a high degree of consistency, the marks or scores produced are almost the same in any situation. To determine the reliability of the test, at least two sets of data need to be obtained through the test scores. Among the procedures that are frequently used to obtain the test reliability are the test-retest method, the parallel forms method, the split half method, Kuder Richardson method and the Cronbach Alpha coefficient method [14-17].

Automated Body Reaction Test (ABRT) is a new device for skills and physical assessment instrument according to the current technological build to measure ability to react, movement and accurately in accordance with a choice stimulus. Objective of this study is to identify the 
validity and reliability ABRT for studens age 7 to 17 years old in Malaysia.The correlation study involves a total of 474 subjects aged 7 to 17 years old were randomly selected for the construct validity test $(\mathrm{N}=330)$ and reliability test $(\mathrm{N}=144)$.

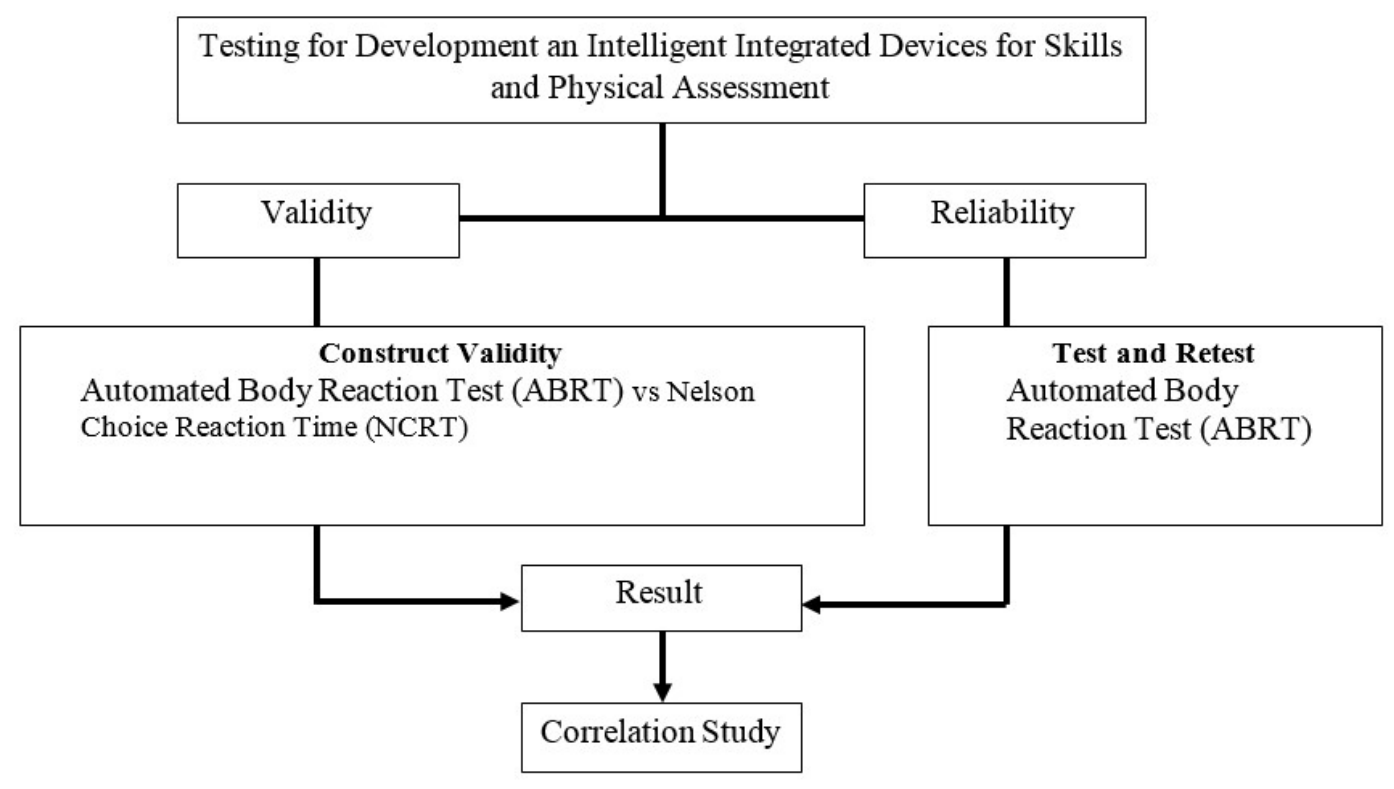

Fig.1. Conceptual Study

Based on Figure 1, Automated Body Reaction Test (ABRT) for Skills and Physical Assessment tool was tested for validity and reliability. A total of 330 subjects aged 7 to 9 years old (each group 30 subjects), 10 to 12 years old (each group 30 subjects), 13 to 15 years old (each group 30 subjects) and 13 to 15 years old (each group 30 subjects) were randomly selected for the construct validity test. The ABRT test score were correlated with Nelson Choice Reaction Time (NCRT) test score to find the validity for both test. The reliability test conducted by using test retest prosedures. A total of 144 subjects were ramdomly selected among age groups. 


\section{RESULTS AND DISCUSSION}

\subsection{Construct validity of Automated Body Reaction Test}

Table 1. Validity of Automated Body Reaction Test Years $7-9(\mathrm{n}=90)$

\begin{tabular}{llccccc}
\hline No & Test & Year & Mean & SD & r & Sig \\
\hline 1. & Automated Body Reaction Test (ABRT) & & 56.80 & 7.87 & & \\
& Nelson Choice Reaction Time (NCRT) & 7 & 55.61 & 7.34 & $0.72^{*}$ & 0.00 \\
& Automated Body Reaction Test (ABRT) & & 52.67 & 9.87 & & \\
2. & Nelson Choice Reaction Time (NCRT) & & 51.38 & 9.60 & $0.76^{*}$ & 0.00 \\
& Automated Body Reaction Test (ABRT) & & 53.29 & 6.28 & & \\
3. $\quad$ Nelson Choice Reaction Time (NCRT) & & 56.82 & 6.92 & $0.78^{*}$ & 0.00 \\
& Automated Body Reaction Test (ABRT) & & 54.22 & 8.29 & & \\
4. $\quad$ Overall & 54.53 & 8.33 & & \\
& Nelson Choice Reaction Time (NCRT) & & $543^{*}$ & 0.00 \\
\hline
\end{tabular}

*Correlation is significant at the 0.01 level (2-tailed)

Based on table 1, the finding shows that the validity for ABRT were 7 years $(r=0.72), 8$ years $(\mathrm{r}=0.76)$ and 9 years $(\mathrm{r}=0.78)$. The overall validity for Level 1 Years $7-9$ is $(\mathrm{r}=0.73)$.

Table 2. Validity of Automated Body Reaction Test Years $10-12(\mathrm{n}=90)$

\begin{tabular}{|c|c|c|c|c|c|c|}
\hline No & Test & Year & Mean & SD & $\mathrm{r}$ & Sig \\
\hline \multirow[t]{2}{*}{1.} & Automated Body Reaction Test (ABRT) & \multirow{2}{*}{10} & 53.80 & 6.97 & \multirow{2}{*}{$0.72 *$} & \multirow{2}{*}{0.00} \\
\hline & Nelson Choice Reaction Time (NCRT) & & 54.51 & 6.84 & & \\
\hline \multirow{2}{*}{2.} & Automated Body Reaction Test (ABRT) & \multirow{2}{*}{11} & 58.10 & 7.97 & \multirow{2}{*}{$0.78 *$} & \multirow{2}{*}{0.00} \\
\hline & Nelson Choice Reaction Time (NCRT) & & 57.85 & 8.53 & & \\
\hline \multirow{2}{*}{3.} & Automated Body Reaction Test (ABRT) & \multirow{2}{*}{12} & 42.65 & 6.21 & \multirow{2}{*}{$0.73 *$} & \multirow{2}{*}{0.00} \\
\hline & Nelson Choice Reaction Time (NCRT) & & 42.82 & 5.40 & & \\
\hline \multirow{2}{*}{4.} & Automated Body Reaction Test (ABRT) & \multirow{2}{*}{ Overall } & 51.47 & 9.64 & \multirow{2}{*}{$0.87 *$} & \multirow{2}{*}{0.00} \\
\hline & Nelson Choice Reaction Time (NCRT) & & 51.66 & 9.55 & & \\
\hline
\end{tabular}

*Correlation is significant at the 0.01 level (2-tailed) 
Based on table 2, the finding shows that the validity for ABRT were 10 years $(r=0.72), 11$ years $(r=0.78)$ and 12 years $(r=0.73)$. The overall validity for Level 2 Years $10-12$ is $\quad(r=$ $0.87)$.

Table 3. Validity of Automated Body Reaction Test 13-15 Years ( $\mathrm{n}=90)$

\begin{tabular}{|c|c|c|c|c|c|c|}
\hline No & Test & Year & Mean & SD & $\mathrm{r}$ & Sig \\
\hline 1. & $\begin{array}{l}\text { Automated Body Reaction Test (ABRT) } \\
\text { Nelson Choice Reaction Time (NCRT) }\end{array}$ & 13 & $\begin{array}{l}82.74 \\
82.97\end{array}$ & $\begin{array}{l}10.24 \\
10.62\end{array}$ & $0.88^{*}$ & 0.00 \\
\hline 2. & $\begin{array}{l}\text { Automated Body Reaction Test (ABRT) } \\
\text { Nelson Choice Reaction Time (NCRT) }\end{array}$ & 14 & $\begin{array}{l}83.09 \\
82.38\end{array}$ & $\begin{array}{l}8.55 \\
8.31\end{array}$ & $0.86^{*}$ & 0.00 \\
\hline 3. & $\begin{array}{l}\text { Automated Body Reaction Test (ABRT) } \\
\text { Nelson Choice Reaction Time (NCRT) }\end{array}$ & 15 & $\begin{array}{l}81.75 \\
80.35\end{array}$ & $\begin{array}{l}7.64 \\
7.71\end{array}$ & $0.87^{*}$ & 0.00 \\
\hline 4. & $\begin{array}{l}\text { Automated Body Reaction Test (ABRT) } \\
\text { Nelson Choice Reaction Time (NCRT) }\end{array}$ & Overall & $\begin{array}{l}82.53 \\
81.90\end{array}$ & $\begin{array}{l}8.83 \\
8.94\end{array}$ & $0.87^{*}$ & 0.00 \\
\hline
\end{tabular}

*Correlation is significant at the 0.01 level (2-tailed)

Based on table 3, the finding shows that the validity for aABRT were 13 years $(r=0.88), 14$ years $(r=0.86)$ and 15 years $(r=0.87)$. The overall validity for lower secondary is $(r=$ 0.87).

Table 4. Validity of Automated Body Reaction Test $16-17$ Years $(\mathrm{n}=90)$

\begin{tabular}{|c|c|c|c|c|c|c|}
\hline No & Test & Years & Mean & SD & $\mathrm{r}$ & Sig \\
\hline 1. & $\begin{array}{l}\text { Automated Body Reaction Test (ABRT) } \\
\text { Nelson Choice Reaction Time (NCRT) }\end{array}$ & 16 & $\begin{array}{l}50.78 \\
50.09\end{array}$ & $\begin{array}{l}10.39 \\
9.25\end{array}$ & $0.87^{*}$ & 0.00 \\
\hline 2. & $\begin{array}{l}\text { Automated Body Reaction Test (ABRT) } \\
\text { Nelson Choice Reaction Time (NCRT) }\end{array}$ & 17 & $\begin{array}{l}53.12 \\
53.22\end{array}$ & $\begin{array}{l}9.70 \\
9.47\end{array}$ & $0.92 *$ & 0.00 \\
\hline 3. & $\begin{array}{l}\text { Automated Body Reaction Test (ABRT) } \\
\text { Nelson Choice Reaction Time (NCRT) }\end{array}$ & Overall & $\begin{array}{l}51.96 \\
51.66\end{array}$ & $\begin{array}{c}10.03 \\
9.41\end{array}$ & $0.89 *$ & 0.00 \\
\hline
\end{tabular}

*Correlation is significant at the 0.01 level (2-tailed) 
Based on table 4, the finding shows that the validity for ABRT were 16 years $(r=0.87)$ and 17 years $(r=0.92)$. The overall validity for upper secondary is $(r=0.89)$. Based on the finding, all test showed the value $(r>0.70)$ indicates that the instrument has highly validity and acceptable [18-20].

\subsection{Reliability of Automated Body Reaction Test}

Table 5. Reliability of Automated Body Reaction Test ( $=144)$

\begin{tabular}{|c|c|c|c|c|c|}
\hline No & Test & Mean & SD & $\mathrm{r}$ & Sig \\
\hline \multicolumn{6}{|c|}{ Years $7-9(n=49)$} \\
\hline \multirow[t]{3}{*}{1} & Body Reaction Test (BRT) Test 1 & 26.16 & 4.65 & \multirow{2}{*}{$0.90^{*}$} & \multirow{2}{*}{0.00} \\
\hline & Body Reaction Test (BRT) Test 2 & 25.84 & 5.47 & & \\
\hline & \multicolumn{5}{|c|}{ Years $10-12(n=36)$} \\
\hline \multirow[t]{2}{*}{2} & Body Reaction Test (BRT) Test 1 & 28.61 & 4.70 & \multirow{2}{*}{$0.87 *$} & \multirow{2}{*}{0.00} \\
\hline & Body Reaction Test (BRT) Test 2 & 29.22 & 5.10 & & \\
\hline \multicolumn{6}{|c|}{$13-15$ Years $(n=30)$} \\
\hline \multirow[t]{2}{*}{3} & Body Reaction Test (BRT) Test 1 & 29.17 & 5.70 & & \multirow{2}{*}{0.00} \\
\hline & Body Reaction Test (BRT) Test 2 & 32.34 & 6.54 & $0.88 *$ & \\
\hline \multirow{3}{*}{4} & \multicolumn{5}{|c|}{$16-17$ Years $(n=30)$} \\
\hline & Body Reaction Test (BRT) Test 1 & 32.71 & 5.68 & \multirow{2}{*}{$0.88^{*}$} & \multirow{2}{*}{0.00} \\
\hline & Body Reaction Test (BRT) Test 2 & 34.87 & 6.27 & & \\
\hline
\end{tabular}

*Correlation is significant at the 0.01 level (2-tailed)

Based on table 5 , the finding shows that the reliability for BRT test age $7-9$ years $(r=0.90)$, $10-12$ years $(\mathrm{r}=0.87), \quad 13-15$ years $(\mathrm{r}=0.88), \quad$ and $16-17$ years $(\mathrm{r}=0.88)$ using the Intelligent Integrated Devices for Skills and Physical Assessment. Based on the finding, all test showed the value $(r>0.70)$ indicates that the instrument has reliable and acceptable [18-20].

\section{CONCLUSION}


Automated Body Reaction Test (ABRT) for Skills and Physical Assessment tool was tested for validity and reliability. A total of 330 subjects aged 7 to 17 years old (each group 30 subjects) were randomly selected for the construct validity and reliability test. Based on the finding, Intelligent Integrated Devices (Body Reaction Test) for Skills and Physical Assessment Tools showed high validity and reliability. This finding shows that Automated Body Reaction Test (ABRT) is a new device for skills and physical assessment instrument are acceptable to evulate time reaction for student age 7 to 17 years old to measure ability to react, movement and accurately in accordance with a time reaction.

\section{ACKNOWLEDGMENTS}

This work was supported by Meas-Tech Solutions Sdn. Bhd. under Grant Code: 2016-0205-106-29.

\section{REFERENCES}

[1] Miller M G, HernimanJJ, Rickard M D, Cheatham CC, Michael TJ. The effects of a 6-week plyometric training program on agility. J Sport Sci Med, 2006, 5:459-465

[2] Clark,Metcalfe's. The mountain of motor development: A metaphor. In Clark J E Humphrey J. Motor development: Research and reviews. Reston, Va: NASPE Publications, 2002, pp. 163-190.

[3] Payne V G, Isaacs L D. Models of lifespan motor development: Human motor development. New York, Amerika: McGraw-Hill, 2012, pp. 3.

[4] Gentile AM. Skill acquisition: Action, movement, and neuromotor processes. In J H Carr \& R B Shepherd (Eds.), Movement science: Foundations for physicaltherapy (2 ${ }^{\text {nd }}$ ed.). Rockville, MD: Aspen, 2000, pp. 111-187.

[5] Livesey D, Mow M L, Toshack T, Zheng Y. 2010, 37(4), 581-588,doi:10.1111/j.1365-2214.2010.01183.x

[6] Hands B.Journal of Science and Medicine in Sport, 2008, 11(2), 155-162. doi.org/10.1016/j.jsams.2007.02.012

[7] Milanese F G, Cesari C, Zancanaro C. Journal of Human Sport and Exercise. 2010, 5, 265-279, DOI:10.4100/jhse.2010.52.14 
[8] Imanipour V, Mahboubeh M., Salma H, Hamed Y, Shahedi V,Mahdi A. The effect of mental practice on response time via Nelson's speed of movement test. European Journal of Experimental Biology, 2012, 2(6), 2444-2450

[9] Bond C.Educational Psychology in Practice, 2011, 27(2), 143-153, doi.org/10.1080/02667363.2011.567093

[10] LeGear M, Greyling L, Sloan E, Bell R, Williams B, Naylor P, Temple V.International Journal of Behavioral Nutrition and Physical Activity, 2012, 9(29), 1-5, doi.org/10.1186/1479-5868-9-29

[11] Vanttinen T, Blomqvixt M, Nyman K,Hakkinen K. Journal of strength and conditioning research, 2011, 25(12), 3342-3351, doi: 10.1519/JSC.0b013e318236d0c2

[12] Mas Murni A. Keberkesananlatihankecergasanfizikalberasaskankemahiran motor terhadapatlethokiUniversitiTeknologi Malaysia, 2012, Faculty of Education,UniversitiTeknologi Malaysia.

[13] Mastura Y. Tahapprestasikecergasanfizikalberasaskankemahiran motor bagipasukan bola keranjangSekolahTun Fatimah Johor Bahru, 2009, Faculty of Education, UniversitiTeknologi Malaysia.

[14] Ahmad H. Pengukurankecergasan motor. TanjongMalim: Quantum Books, 2003, pp. $10-25$.

[15] Leedy P D, Ormrod J. Practical research: Planning and design $\left(9^{\text {th }}\right.$ ed. $)$. NJ: Prentice Hall, 2010, pp. 94-96.

[16] Ahmad H. PanduanAnalisis Data SecaraEfisien: Panduanlengkapberajahuntukmenganalisis data.Cheras: Dubook Press Sdn. Bhd, 2014, pp. $58-62$.

[17] Chua, Y P. Research methods. Shah Alam: McGraw-Hill, 2006, pp.75-89.

[18] Mohd Izwan S, Norkhalid S, Gunathevan E.Procedia - Social and Behavioral Sciences. 2015, 195 (12), 814-820, doi:10.1016/j.sbspro.2015.06.184

[19] Norkhalid S, Julismah J, Mohd Izwan S, Gunathevan E. Asian Social Science. 2015, 11 (23), 12-21, doi:10.5539/ass.v1 $1 \mathrm{n} 23 \mathrm{p} 12$

[20] Rink J E. Teaching physical education for learning (4 ${ }^{\text {th }}$ ed.). New York: McGraw Hill, 2002, pp.243-244. 
How to cite this article:

N. Salimin, M. I. Shahril, M. A. Md. Taff, G. Elumalai, R. Ahmad, H. M. Hizan, A. Hashim, M. F. Abdullah and S. K. Syed Ali. Construct validity and reliability of automated body reaction test. Fundam. Appl. Sci., 2017, 9(6S), 1207-1218. 